\title{
EDITORIAL
}

\section{THE ROLE OF PRIMARY CARE IN THE RECOGNITION OF AND RESPONSE TO DEMENTIA}

\author{
T. KOCH'1, S. ILIFFE² FOR THE EVIDEM PROGRAMME
}

1. Clinical Associate in Academic Primary Care in the Department of Primary Care and Population Health, at University College London; 2. Professor of Primary Care for Older People at University College London and chief investigator on the EVIDEM (Evidence-based Interventions in Dementia) programme (www.evidem.org.uk)

\section{Introduction}

Because of population ageing, the prevalence of dementia is on the rise globally. It is estimated that there will be 35.6 million people living with dementia worldwide by 2010 , and it is thought that the prevalence is set to almost double to 65.7 million by 2030 (1). From a Global Burden of Disease perspective, it contributes $11.2 \%$ of all years lived with a disability, which is higher than stroke $(9.5 \%)$, heart disease $(5 \%)$ and cancer (2.4\%) (2).

There is much debate about which health professional discipline is best-placed to recognise dementia, make a diagnosis, and manage the care of dementia patients. It has been postulated that primary care practitioners are in the ideal position to be able to recognise the symptoms and signs of early dementia, and trigger the necessary investigations to establish a diagnosis (3) because of their close relationship with patients, their ability to monitor and evaluate patients over time, and therefore to identify changes to their cognition and mood. However, dementia does not have a great impact on the workload of an average General Practitioner (GP). For example, in the United Kingdom (UK), a GP in a demographically average area might diagnose one or two new patients each year and have twelve to fifteen patients with dementia on a list of 2000 patients (4).

Perhaps because of these small numbers and the lack of educative exposure to patients with dementia, early detection of dementia is difficult to achieve, and delayed diagnosis has been shown to be a problem for primary care practitioners the world over (5-7). Moreover, according to Bamford et al, diagnosis of dementia can take between 18 to 30 months, and in the extreme up to 4 years (8).

The barriers to primary care practitioners detecting and managing dementia effectively are well-established. These can be classified into three categories: patient or societal factors, practitioner factors, and system factors. The former includes stigma or delayed presentation $(9,10)$. The practitioner factors include diagnostic uncertainty or perceived lack of knowledge $(11,12)$, therapeutic nihilism (13), and concerns about disclosing the diagnosis (14). These factors are shared by primary care and community nurses (15). Finally the health care system is responsible for many of the barriers, including for example, time or financial constraints $(10,16)$, and a perceived lack of support for the primary care practitioner $(9$, 12).

Patient or societal barriers need to be addressed with public health initiatives and health awareness campaigns. We will focus on possible strategies that can be employed to overcome the practitioner and system barriers.

In our view there are three possible approaches that can be used to tackle the issues outlined above. The first would involve incentivising the primary care practitioners financially, which could improve their motivation to enhance their detection rates and management of dementia. The second would be to enhance the skills of primary care practitioners by improving training and education, thus overcoming their perceived lack of knowledge, diagnostic uncertainty, and therapeutic nihilism. The third would be to change the system by using case managers to coordinate care, introduce a multidisciplinary approach, and remove some of the burden of detection and management from the primary care practitioner. These three approaches will be examined in more detail.

\section{Financial Incentivisation}

Lack of time or of financial remuneration have been frequently cited as limitations to primary care practitioners being able to detect or manage patients with dementia. These obstacles arise because of the real or perceived amount of extra time and resources needed to diagnose and comprehensively manage these patients and their caregivers, and has been most notable in countries where the primary care practitioners are remunerated directly for the services that they provide, such as in the United States of America (USA), Canada, or Ireland. Evidence exists to show that if primary care practitioners are appropriately reimbursed, then the quality of care can improve. Campbell et al (17) demonstrated that the Quality and Outcomes Framework (QOF) (18) (which is the payment-forperformance framework used in the UK) led to improved quality of care for at least two of the clinical domains included, and Roland claims that this rate supersedes the trajectory of improvement that those conditions were on as a result of auditing - a practice that was introduced a few years beforehand (19). Moreover, when care indicators have been incentivised in the US, physicians have responded positively and the quality of care has increased (20). In comparison, care 


\section{THE ROLE OF PRIMARY CARE IN THE RECOGNITION OF AND RESPONSE TO DEMENTIA}

has not changed for the un-incentivised clinical conditions in the UK (21), and this finding has been replicated in the USA (22). Although there is a dearth of dementia-specific evidence in this field, we think it is plausible to argue that if the primary care practitioners felt that they were being adequately reimbursed for investing the extra resources needed to achieve high standards of care, then detection rates and management of dementia patients would improve.

\section{Enhancing Skills}

Several interventions which target practitioner barriers have been proposed and tested. Any approach needs to bring about behaviour change rather than simply improving knowledge, because so many of the problems are perceived rather than necessarily being actual. Different educational strategies have been trialled, with varying success. Seminar-based interventions seem unable to demonstrate any improvement in the diagnostic or management outcomes measured (23). Conversely, facilitated educational strategies were able to improve knowledge and self-directed learning (24), and practice-based workshops and decision-support software improved the detection rate but not the management of dementia (25). In addition, one study trialled three interventions designed to improve primary care practitioners' adherence to guidelines (26). Neither educational seminars nor outreach visits or reminder letters containing recommendations improved detection rates or management. One main limitation of this trial, however, was that the interventions were delivered at primary care practitioner level but the outcomes were measured at practice level. A current randomised controlled trial is testing the effect of tailored educational interventions on concordance with clinical management guidelines at the practice level (www.evidem.org.uk).

\section{Multi-Disciplinary Approach}

Whilst the first two strategies might tackle barriers of finances, uncertainty about diagnosis, perceived lack of knowledge, or therapeutic nihilism, they won't overcome the issues surrounding lack of support - a theme that featured regularly in studies exploring barriers. This hurdle needs to be addressed at a system level, using a multi-disciplinary methodology.

It has been suggested that instilling a culture of multidisciplinary teamwork can improve detection and management of dementia in primary care, and that improving referral pathways is preferable even to introducing guidelines (12). Several studies in the US have introduced a case manager at the primary care level in order to attempt to achieve this. Their role varied depending on the study, but comprised assessment, monitoring, care-planning, management and coordinating care, and resulted in positive findings in some of the outcomes measured. These included care that was more concordant with guidelines and increased referrals to community services (27), and improved patient satisfaction levels and reduced rates of depression (28). In spite of these promising results, the role is yet to be tried outside the US health system, and the extra utilisation of health care resources might be prohibitive in some countries.

\section{Conclusion}

Despite identifying what appear to be effective methods to improve primary care services via financial remuneration and enhancing primary care practitioners' abilities to detect dementia through educational interventions, there are clear limitations to relying on these strategies as the sole routes to improving care for this cohort. Whilst it has been shown that remunerating primary care practitioners for their services can enhance clinical care, and that educational interventions may improve at least detection rates of dementia, the completeness of these effects remain uncertain (especially with regards to the management of dementia). Moreover, using a multidisciplinary approach enriches the care experience for patient, caregiver, and health professionals but here the size of the effect is as yet untested in most health systems. For these reasons careful thought ought to be given to the development of more efficient and innovative care provision and pathways that will be able to amalgamate all three strategies, to a lesser or greater degree. Only in this way will primary care practitioners be able to achieve high standards of care for their patients with dementia (29).

The EVIDEM programme receives financial support from the Department of Health National Institute for Health Research (DH/NIHR) Programme Grants for Applied Research funding scheme. The views and opinions expressed in this editorial do not necessarily reflect those of the DH/NIHR.

\section{References}

1. Alzheimer's Disease International, 2009. World Alzheimer Report http://www.alz.co.uk/research/worldreport/ [accessed27.11.09]

2. WHO. Global burden of dementia in the year 2000. www.who.int/entity/healthin fo/statistics/bod_dementia.pdf

3. Iliffe S, Wilcock J, Austin T, Walters K, Rait G, Turner S, et al. Dementia diagnosis and management in primary care. Dementia 2002;1(1):11-3.

4. Iliffe S, Robinson L, Brayne C, Goodman C, Rait G, Manthorpe J, et al. Primary care and dementia: 1. diagnosis, screening and disclosure. Int J Geriatr Psychiatry 2009;24:895-901.

5. Olafsdottir M, Foldevi M, Marcusson J. Dementia in primary care: why the low detection rate? Scan J Prim Health Care 2001;19:194-8.

6. Boise L, Camicioli R, Morgan D, Rose J, Congleton L. Diagnosing dementia: perspectives of primary care physicians. The Gerontologist 1999;39:457-64.

7. O'Connor D, Pollitt J, Hyde J, Brooke C, Reiss B, Roth M. Do general practitioners miss dementia in elderly patients? BMJ 1998;297:1107-10.

8. Bamford C, Eccles M, Steen N, Robinson L. Can primary care record review facilitate earlier diagnosis of dementia? Family Practice 2007;24:108-16.

9. Teel C. Rural practitioners' experiences in dementia diagnosis and treatment. Aging \& Mental Health 2004;8(5):422-9.

10. van Hout H, Vernooij-Dassen M, Bakker K, Blom M, Grol R. General practitioners on dementia: tasks, practices and obstacles. Paient Education \& Counseling 2000;39:219-25.

11. Cahill S, Clark M, O'Connell H, Lawlor B, Coen R, Walsh C. The attitudes and practices of general practitioners regarding dementia diagnosis in Ireland. Int $\mathrm{J}$ Geriatr Psychiatry 2008;23(663):669.

12. Iliffe S, de Lepeleire J, van Hout H, Kenny G, Lewis A, Vernooij-Dassen M, et al. 


\section{JNHA: CLINICAL NEUROSCIENCES}

Understanding obstacles to the recognition of and response to dementia in different European countries: A modified focus group approach using multinational, multidisciplinary expert groups. Aging \& Mental Health 2005;9(1):1-6.

13. Iliffe S, Wilcock J, Haworth D. Obstacles to shared care for patients with dementia: a qualitative study. Family Practice 2006;353-62.

14. Iliffe S, Wilcock J. The identification of barriers to the recognition of, and response to, dementia in primary care using a modified focus group approach. Dementia 2005;4(1):73-85.

15. Bryans $\mathrm{M}$, Keady J, Turner $\mathrm{S}$, et al. An exploratory survey into primary care nurses and dementia care. Br J Nurs 2003;12(17):1029-37.

16. Hinton L, Franz C, Reddy G, Flores Y, Kravitz R, Barker J. Practice constraints, behavioural problems, and dementia care: primary care physicians' perspectives. J Gen Intern Med 2007;22(11):1487-92.

17. Campbell S, Reeves D, Kontopantelis E, Sibbald B, Roland M. Effects of Pay for Performance on the Quality of Primary Care in England. N Engl J Med 2009;361:368-78.

18. Department of Health. Investing in general practice: the New General Medical Services contract. London: The Stationary Office; 2003.

19. Roland M. The quality and outcomes framework: too early for a final verdict. Br J Gen Pract 2007;July:525-6.

20. Epstein A, Thomas L, Hamel M. Paying physicians for high-quality care. N Engl J Med 2004;350(4):406-10.

21. Steele N, Maisey S, Clark A, et al. Quality of clinical primary care and targeted incentive payments: an observational study. Br J Gen Pract 2007;57:449-54.

22. Ganz D, Wenger $\mathrm{N}$, Roth $\mathrm{C}$, et al. The effect of a quality improvement initiative on the quality of other aspects of health care: the law of unintended consequences? Med Care 2007;45(1):8-18.

23. Sizemore M, Vicioso B, Lorthrop J, Rubin C. Outcome of a pilot dementia training program for primary care physicians. Educational Gerontology 1998;24(1):27-34.

24. Dalsgaard T, Kallerup H, Rosendal M. Outreach visits to improve dementia care in general practice: a qualitative study. Int J for Qual in Health Care 2007;19(5):267-73.

25. Downs M, Turner S, Bryans M, Wilcock J, Keady J, Levin E, et al. Effectiveness of educational interventions in improving detection and management of dementia in primary care: cluster randomised controlled study. BMJ 2006;332(692):696.

26. Waldorff F, Almind G, Makela M, Moller S, Waldemar G. Implementation of a clinical dementia guideline: a controlled study on the effect of a multifaceted strategy. Scan J Prim Health Care 2003;21:142-7.

27. Vickrey B, Mittman B, Connor K, Pearson M, Della Penna R, Ganiats T, et al. The effect of a disease management intervention on quality and outcomes of dementia care. Ann Intern Med 2006;145(713).

28. Clark P, Bass D, Looman W, McCarthy C, Eckhert S. Outcomes for patients with dementia from the Cleveland Alzheimer's managed care demonstration. Aging \& Mental Health 2004;8(1):40-51.

29. Villars H, Oustric S, Andrieu S, Baeyens JP, Bernabei R, Brodaty H, Brummel-Smith K, Celafu C, Chappell N, Fitten J, Frisoni G, Froelich L, Guérin O, Gold G, Holmerova I, Iliffe S, Lukas A, Melis R, Morley JE, Nies H, Nourhashemi F, Petermans J, Ribera Casado J, Rubenstein L, Salva A, Sieber C, Sinclair A, Schindler R., Stephan E, Wong RY, Vellas B. J Nutr Health Aging. 2010; 14(2):110120 